\title{
$1 \quad$ Moringa oleifera coagulation as pretreatment prior to microfiltration for membrane fouling mitigation
}

${ }^{1}$ Department of Advanced Engineering, Graduate School of Engineering, Nagasaki University, 1-14 Bunkyo-machi, Nagasaki 852-8521, Japan

${ }^{2}$ Faculty of Science \& Technology, Ryukoku University,

${ }^{3}$ Centre for Technology in Water and Wastewater, University of Technology Sydney, 


\section{TOC contents}

16

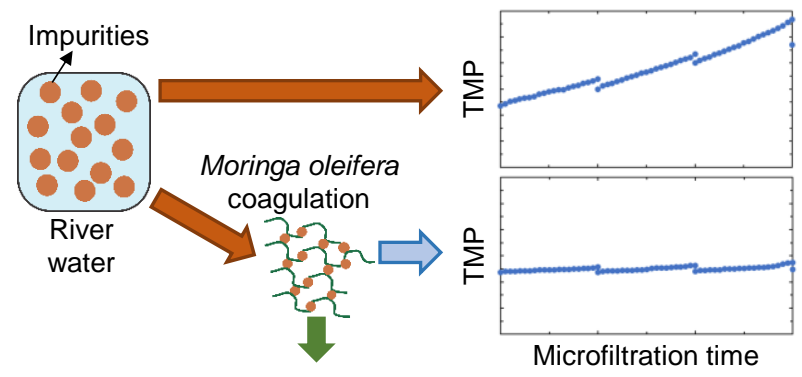

17 Coagulation pretreatment using Moringa oleifera in microfiltration of a river water achieved

18 membrane fouling mitigation and filtered water quality improvement. 


\section{Abstract}

20 Coagulation using Moringa oleifera (MO), a natural coagulant, is an attractive approach in

21 drinking water treatment to break away from conventional chemical coagulation using

22 aluminium or iron salts. This study aimed to evaluate the effect of pre-filtered MO coagulation

23 pretreatment on the fouling mitigation in microfiltration (MF) process. MF treatment of a river

24 water without pretreatment promoted a considerable reduction in membrane permeability (i.e.

25 membrane fouling), which was not sufficiently recovered by conventional backwashing. In

26 contrast, MF treatment after MO coagulation substantially reduced membrane fouling. Over six

27 filtration cycles (or $6 \mathrm{~h}$ filtration period), the fouling mitigation level with MO coagulation was

28 comparable to that with aluminium sulphate (alum) coagulation. In addition, major water quality

29 (turbidity and colour) after MF treatment was equivalent between MO and alum coagulation.

30 Pretreatment by MO coagulation has an advantage of maintaining water $\mathrm{pH}$ after MF treatment.

31 The results obtained here suggest that MO coagulation can be employed as an effective and low-

32 cost fouling mitigation technique for MF process in drinking water treatment. 


\section{Introduction}

34 There is a growing interest in Moringa oleifera (MO) seed as an alternative to chemical

35 coagulants such as aluminium sulphate (alum) and ferric chloride in recent years. ${ }^{1,2}$ In a typical

36 drinking water treatment, coagulation followed by sedimentation and sand filtration plays an

37 important role in removing particulate matter. ${ }^{3} \mathrm{MO}$ seeds contain dimeric cationic proteins, ${ }^{4}$

38 which can be extracted from MO seeds using water or salt solution and used for coagulation

39 applications. ${ }^{5} \mathrm{MO}$ coagulation is based on the net-like structure coagulation mechanism, that is

40 effective for turbidity removal. ${ }^{5}$ For example, previous studies ${ }^{6-8}$ demonstrated that MO

41 coagulation achieved from $60 \%$ to almost complete removal of turbidity for high turbid surface

42 waters with $50-450$ NTU. MO is not toxic; thus, even when coagulation is not correctly

43 performed causing overdosing, no adverse effects on public health are expected in case of

44 overdosing. In addition, given its organic nature, coagulant sludge generated through MO

45 coagulation can be processed for use as animal feed or plant fertilizer. ${ }^{9} \mathrm{MO}$ is a fast growing

46 tree, commonly found in semiarid, tropical and sub-tropical areas including India, South and

47 Central America, Africa and South East Asia. ${ }^{10}$ Thus, MO coagulation is a pragmatic option to

48 provide access to safe drinking water to rural communities in developing countries around the

49 world as stated in the Millennium Development Goals by the United Nation.

50 Gravity driven membrane filtration is another technology that has significantly improved access

51 to safe drinking water. ${ }^{11}$ Notable examples include the Skyjuice ${ }^{12}$ and Aqua CUBE systems, in

52 which water is driven through a microfiltration (MF) by gravity. MF has been widely used for

53 drinking water treatment to reliably remove suspended solids and pathogens such as protozoa

54 and pathogenic bacteria. ${ }^{13,14}$ A major challenge in using MF for low cost drinking decentralised 
55 water treatment is membrane fouling, which is caused by the deposition of colloidal and organic 56 substances on the membrane surface or in the membrane pores and can reduce membrane 57 permeability and separation performance. ${ }^{15-17}$ Membrane fouling in MF can be controlled by 58 frequent backwashing or chemical cleaning. However, these methods are not compatible with 59 decentralised water treatment. A more suitable approach is to apply pre-coagulation prior to MF 60 treatment. $^{18}$

61 The effectiveness of coagulation pretreatment with alum or ferric chloride to mitigate MF 62 membrane fouling has been demonstrated in the literature. ${ }^{19,} 20$ The reduced membrane fouling 63 can be attributed to coagulation process capable of removing suspended solids and dissolved 64 organic matter. ${ }^{21}$ Although alum and ferric coagulation have been successfully used as a 65 membrane fouling mitigation technique in drinking water treatment, the use of these heavy metal 66 coagulants may be inappropriate in some developing countries due to the unaffordable high costs

67 of imported chemicals ${ }^{6}$ and MO coagulation can be an alternative pretreatment. In fact, previous 68 studies have successfully applied MO coagulation to pretreat high turbidity ( $>500$ NTU) waters 69 such as dairy wastewater ${ }^{22,23}$ and secondary oxidation pond effluent ${ }^{24}$ prior to MF operation. MO 70 coagulation pretreatment can possibly substitute backwashing to reduce the complexity of MF 71 operation in drinking water applications, making it more amendable to small rural communities.

72 However, when a low turbidity water (such as river water) was used as the feed, MO coagulation 73 could only achieve about $60 \%$ turbidity removal. ${ }^{2}$ Moreover, since it is an organic based 74 coagulant, MO coagulation prior to MF filtration can result in the considerable increase in 75 organic matter concentration in the pretreated water. ${ }^{25}$ Previous studies ${ }^{26,27}$ have identified that 76 an improvement in the extraction method of MO coagulant can be attained through pre-filtration 
77 of MO seed powder. To date, the pre-filtered MO coagulant has not been applied to the

78 pretreatment of membrane filtration.

79 This study aimed to evaluate the effects of pre-filtered MO coagulation on the fouling mitigation

80 of MF treatment in drinking water applications. MO dose in a surface water with low turbidity

81 was optimised for turbidity removal and fouling mitigation. Thereafter, MO coagulation on the

82 fouling mitigation of MF treatment was evaluated over six filtration cycles, and the results were

83 compared with that of alum coagulation. This study also examined water quality after

84 coagulation followed by MF treatment.

\section{2. Materials and methods}

\section{$86 \quad 2.1 \quad$ Chemicals}

87 Analytical grade alum $\left(\mathrm{Al}_{2}\left(\mathrm{SO}_{4}\right)_{3} \cdot 18 \mathrm{H}_{2} \mathrm{O}\right)$ and sodium chloride $(\mathrm{NaCl})$ were purchased from

88 Wako Pure Chemical Industries (Tokyo, Japan). A stock solution of alum coagulant was

89 prepared in Milli-Q water to obtain $1000 \mathrm{mg}-\mathrm{Al} / \mathrm{L}$. A NaCl solution of $1 \mathrm{M}$ was also prepared in

90 Milli-Q water and used for MO coagulant extraction. Tap water was treated using a reverse

91 osmosis system and used for backwashing water. River from Nagasaki, Japan was used to

92 present surface water. The river water collected in December was stored at $4{ }^{\circ} \mathrm{C}$ and was used

93 within one week.

\section{$94 \quad 2.2 \quad$ MO coagulant}

95 MO seeds were collected from Tamil Nadu, India. The MO seeds were first ground into powder.

96 Then $1 \mathrm{~g}$ of MO powder was dissolved with $100 \mathrm{~mL}$ Milli-Q water at $30^{\circ} \mathrm{C}$. Thereafter, the 
97 obtained MO solution was stirred for $5 \mathrm{~min}$ and allowed to settle for $10 \mathrm{~min}$. The supernatant of

98 MO solution was filtered with a $0.45 \mu \mathrm{m}$ filter (Thermo Scientific, Waltham, NA, USA) and the

99 filtrate was discarded. Solid residue on the filter was washed by $100 \mathrm{~mL}$ of $1 \mathrm{M} \mathrm{NaCl}$. The

100 obtained solution was filtered again via the same protocol described above (i.e. stirred for $5 \mathrm{~min}$,

101 settled for $10 \mathrm{~min}$, and filtered to obtain $100 \mathrm{~mL}$ of clear filtrate). The final filtrate was used as

102 MO coagulant for subsequent experiments.

\section{$103 \quad 2.3 \quad$ Membrane module and filtration system}

104 A hollow fibre polyvinylidene fluoride (PVDF) MF membrane with nominal pore size of $0.1 \mu \mathrm{m}$ 105 (Microza ${ }^{\circledR}$ USP-043, Asahi Kasei, Tokyo, Japan) was used in this study. The MF membrane was 106 supplied in a module with length of $132 \mathrm{~mm}$, external diameter of $1.4 \mathrm{~mm}$, internal diameter of $1070.7 \mathrm{~mm}$ and effective membrane area of $120 \mathrm{~cm}^{2}$. The membrane module is designed to operate 108 in the inside-out filtration orientation. The module is integrated into a laboratory-scale dead-end 109 filtration system comprising $2 \mathrm{~L}$ glass feed reservoir, flow meter, a peristaltic pump for filtration 110 (Kros Flo ${ }^{\circledR}$ Research pump, Spectrum Laboratories, CA, USA), a peristaltic pump for 111 backwashing (Q-100, Tacmina, Osaka, Japan), a temperature control unit (ACE-2000, Tokyo 112 Rikakikai, Tokyo, Japan), vales and pressure gauges (Fig. S1).

\section{$113 \quad 2.4 \quad$ Experimental protocols}

\section{$114 \quad$ 2.4.1 Coagulation experiment}

115 Coagulation experiments were performed using a jar test system (JMD-3E, Miyamoto Riken

116 Industry, Osaka, Japan). This jar test system was equipped with a series of $1 \mathrm{~L}$ beakers and 117 stirring shafts. The stirring speed of these shafts can be changed automatically. Each beaker was 
118 filled with $1 \mathrm{~L}$ of river water. Immediately after coagulant addition, the beakers were rapidly

119 mixed for $2 \mathrm{~min}$ at $150 \mathrm{rpm}$. The coagulant dose was from 0 to $8 \mathrm{~mL}-\mathrm{MO} / \mathrm{L}$ and 0 to $10 \mathrm{mg}-\mathrm{Al} / \mathrm{L}$

120 for MO and alum, respectively. After rapid mixing, the water was flocculated for 30 min at a

121 mixing speed of $30 \mathrm{rpm}$. Then, the beakers were left undisturbed for sedimentation for $1 \mathrm{~h}$. The

122 supernatant was then collected for subsequent filtration experiments and water quality analysis.

\section{$123 \quad$ 2.4.2 MF treatment}

124 Prior to each MF filtration experiment, integrity of the membrane module was confirmed by 125 measuring the clean water permeability at $20^{\circ} \mathrm{C}$. Thereafter, the feed reservoir was filled with a 126 river water (a) without pre-treatment, (b) after MO coagulation or (c) after alum coagulation. 127 Each filtration cycle comprised of two steps: filtration and backwashing. Filtration was 128 conducted at the permeate flux of $140 \mathrm{~L} / \mathrm{m}^{2} \mathrm{~h}$ (at $20^{\circ} \mathrm{C}$ ) for $1 \mathrm{~h}$. Membrane fouling was 129 monitored by the transmembrane pressure (TMP). At the end of the filtration step, backwashing 130 was applied using clean water at the flux of $280 \mathrm{~L} / \mathrm{m}^{2} \mathrm{~h}\left(\right.$ at $20{ }^{\circ} \mathrm{C}$ ) for $1 \mathrm{~min}$. The next filtration

131 cycle was then repeated as described above. After each experiment, chemical cleaning was used 132 to restore the membrane permeability to within $1 \%$ the initial value. Chemical cleaning was 133 conducted by soaking the membrane overnight in $1 \%$ sodium hydroxide and 400 ppm of sodium 134 hypochlorite at room temperature. The membrane was then rinsed with a copious amount of 135 clean water to remove any residual chemicals.

\section{$136 \quad 2.5 \quad$ Analytical techniques}

137 The water quality parameters analysed here include turbidity, colour, $\mathrm{pH}$, electrical conductivity 138 and total organic carbon (TOC). Turbidity and colour measurements were conducted using water 139 analyser turbidity meter (WA1, Nippon Denshoku, Tokyo, Japan). The $\mathrm{pH}$ was measured using a 
$140 \mathrm{pH}$ meter (SK-620 PH II, Sato, Tokyo, Japan). Electrical conductivity was measured using a 141 conductivity meter (AS 710, As One Corporation, Shanghai, China). TOC was measured using a 142 total organic analyser (TOC-VCSD, Shimadzu, Kyoto, Japan). Zeta potential of substances in 143 water was analysed using a rectangular micro-electrophoresis cell (ZEECOM ZC-2000, Microtec

144 Co., Funabashi, Japan). The zeta potential of 30 particles was measured and averaged in this 145 study. Size distribution of particles over $100 \mathrm{~nm}$ (equivalent to membrane pore size) in water 146 samples was measured using NanoSight LM10 (Malvern Panalytical, Malvern, UK), which 147 utilizes light scattering and Brownian motion for the characterization of nanometer size particles.

\section{$148 \quad 2.6 \quad$ Fouling model description}

149 Membrane fouling in constant flow of MF typically progresses following one of the following 150 models: complete blocking, standard blocking, intermediate blocking, or cake filtration models.

151 In general, pore blocking occur immediately after the start of filtration, which is followed by 152 cake filtration. ${ }^{28,29}$ These four modes of fouling can be expressed as follows: ${ }^{30}$

$$
\frac{d P_{t}}{d t}=k\left(\Delta P_{t}\right)^{n}
$$

154 where $t=$ filtration time $[\mathrm{min}], P_{t}=$ transmembrane pressure $[\mathrm{kPa}]$ at filtration time $t, k=\mathrm{a}$ 155 constant of the fouling law, and $n=$ the fouling index. Predominant fouling mechanisms (i.e. 156 complete blocking, standard blocking, intermediate blocking, or cake filtration) can be

157 determined based on the fouling index $(n)\left(2.0,1.5,1.0\right.$, and 0 , respectively) ${ }^{30}$ This study used 158 the pressure data collected every 6 min was used for the calculation. 


\section{Results and discussion}

\section{$160 \quad 3.1 \quad$ Coagulation}

161 Coagulant doses of MO and alum coagulants were optimised based on the removal of turbidity 162 and colour. The optimum coagulant doses of $\mathrm{MO}$ and alum were at $2 \mathrm{~mL}-\mathrm{MO} / \mathrm{L}$ and $4 \mathrm{mg}-\mathrm{Al} / \mathrm{L}$,

163 respectively (Fig. 1). MO coagulation reduced turbidity and colour from 7.8 to 1.1 NTU and 164 from 8.7 to 2.4 PCU, respectively. Alum coagulation resulted in better turbidity and colour 165 removal, achieving 0.1 NTU and 0.8 PCU after coagulation, respectively. The optimum turbidity 166 removal by alum was $99.7 \%$, which was considerably better than that by MO (86\%). Similarly, 167 alum coagulation resulted in $91 \%$ colour removal, which was higher than MO coagulation (72\%)

168 (Fig. 1). Lower turbidity and colour removal efficiencies by MO coagulant can be explained by 169 their lighter and smaller flocs compared to those from alum. MO flocs had poor settleability as 170 previously reported by Okuofu. ${ }^{31}$ For both MO and alum, increasing the coagulant dose beyond 171 the optimum value resulted in increased residual turbidity and colour. Over-dose of MO can 172 cause the saturation of the polymer bridge sites and increased charge repulsion due to MO's 173 cationic poly-electrolyte. ${ }^{8}$ These phenomena can destabilize colloids and particles, inhibiting the 174 removal of turbidity. Results in Fig. 1 indicate that MO coagulant dose needs to be precisely 175 regulated to optimise turbidity removal. 
(a) MO
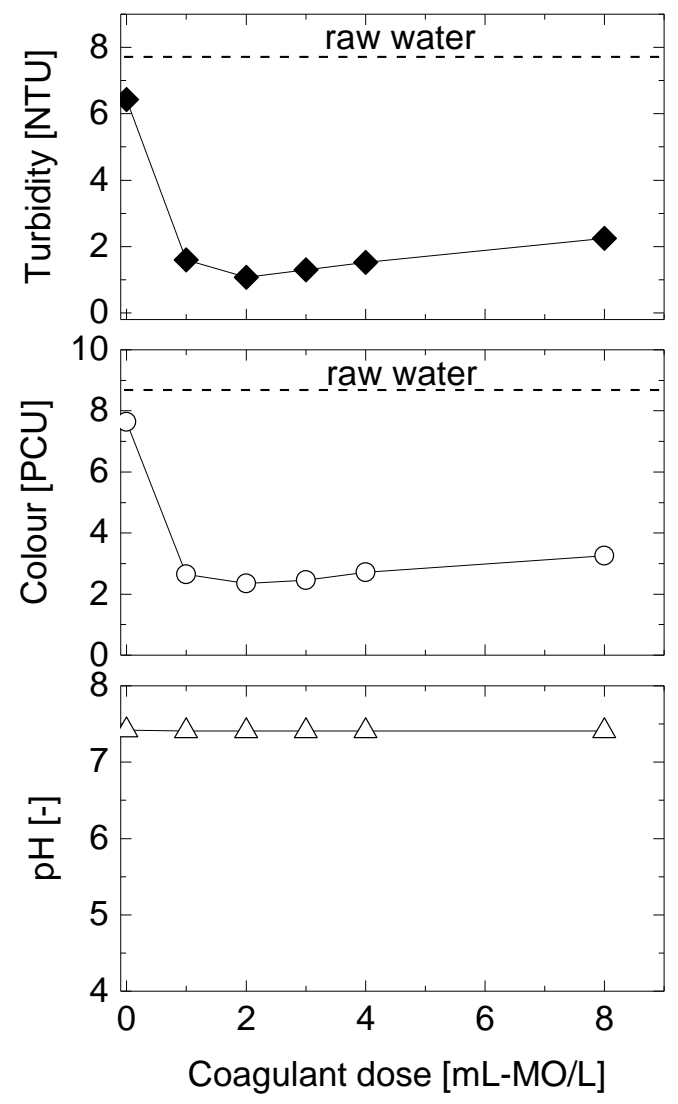

(b) Alum
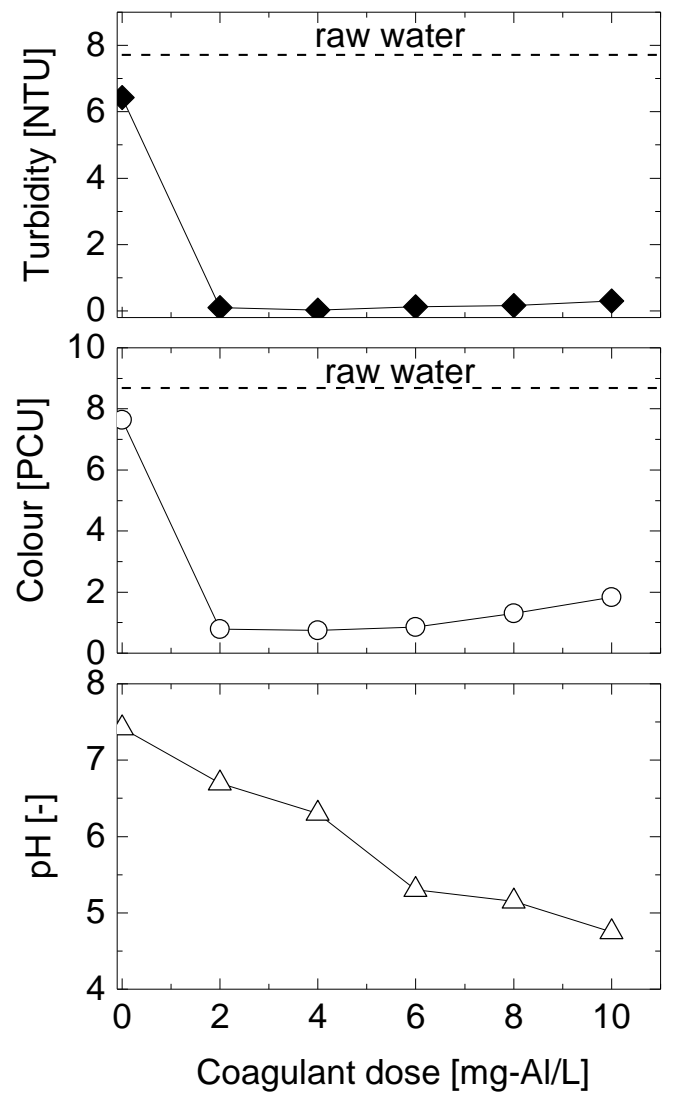

176

177

178

179

180

181

182 increased to $4 \mathrm{mg}-\mathrm{Al} / \mathrm{L}$. On the other hand, a small but discernible increase in conductivity was

183 observed from 270 to $286 \mu \mathrm{S} / \mathrm{cm}$ at the optimum MO dose (Table 1). The increase in

184 conductivity can be ascribed to the addition of $\mathrm{NaCl}$ used for extracting $\mathrm{MO}$ coagulation as

185 described in section 2.2. In addition to conductivity, MO coagulation resulted in a slight increase

186 in TOC concentration, from 15.3 to $15.7 \mathrm{mg} / \mathrm{L}$ at the optimum dose. An increase in the 
187 concentration of organic matter in treated water is one of the major drawbacks of MO. ${ }^{8,9,32}$ In

188 contrast, alum coagulation could achieve about $8 \%$ TOC removal (Table 1). The reduction in

189 TOC concentration in alum coagulation is mainly due to adsorption and complexation with

190 positively charged aluminium ions under acidic conditions, forming insoluble particulate

191 aggregates. ${ }^{33}$

192 Table 1 - Water quality before and after coagulation at their optimum doses (2 mL-MO/L and 4 $193 \mathrm{mg}-\mathrm{Al} / \mathrm{L})$.

\begin{tabular}{lccc}
\hline Parameter & $\begin{array}{c}\text { Untreated } \\
\text { water }\end{array}$ & $\begin{array}{c}\text { MO-treated } \\
\text { water }\end{array}$ & $\begin{array}{c}\text { Alum-treated } \\
\text { water }\end{array}$ \\
\hline Turbidity $(\mathrm{NTU})$ & 7.8 & 1.1 & 0.1 \\
Colour $(\mathrm{PCU})$ & 8.7 & 2.4 & 0.8 \\
Conductivity $(\mu \mathrm{S} / \mathrm{cm})$ & 270 & 286 & 351 \\
TOC $(\mathrm{mg} / \mathrm{L})$ & 15.3 & 15.7 & 14.0 \\
$\mathrm{pH}$ & 7.4 & 7.4 & 6.3 \\
\hline
\end{tabular}

$194 \quad 3.2 \quad$ Optimisation of coagulant dose for fouling mitigation

195 Results from MO optimisation experiments were used to evaluate the performance of MO 196 coagulation pretreatment to mitigate MF membrane fouling. MF treatment of the river water 197 without pretreatment resulted in a rapid increase in TMP from 12 to $17 \mathrm{kPa}$ within the first 198 filtration cycle (0-60 min) (Fig. 2). Moreover, backwashing with clean water was not capable of 199 restoring membrane permeability. As a result, after three filtration cycles TMP reached $24 \mathrm{kPa}$, 200 twice higher than the initial TMP. 


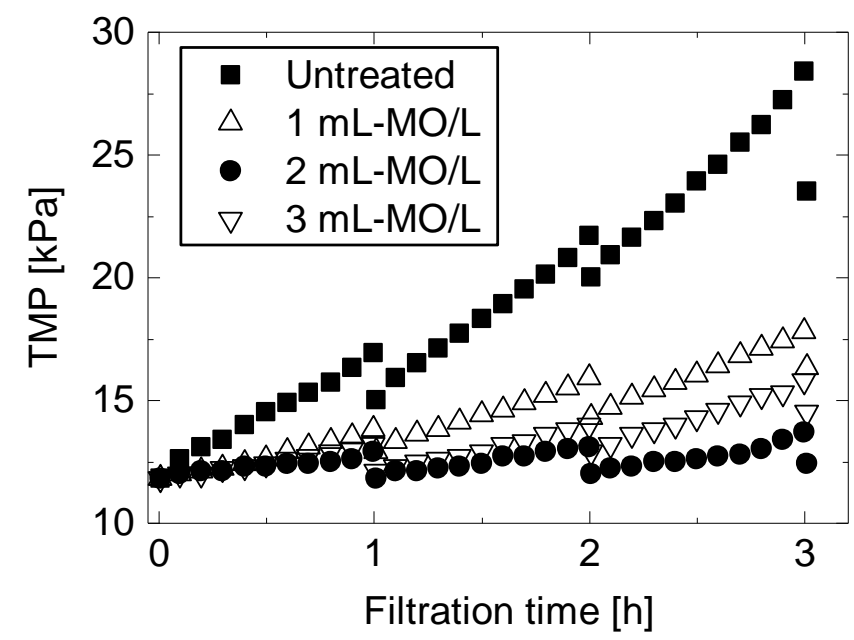

Filtration time $[\mathrm{h}]$

202 Fig. 2 - TMP increase in MF treatment of waters treated with MO coagulant (permeate flux = $203140 \mathrm{~L} / \mathrm{m}^{2} \mathrm{~h}$, backwashing flux $=280 \mathrm{~L} / \mathrm{m}^{2} \mathrm{~h}$ and backwashing time $=1 \mathrm{~min}$ ).

204 MO coagulation performed prior to MF effectively reduced membrane fouling at all MO doses 205 selected here (1, 2 and $3 \mathrm{~mL}-\mathrm{MO} / \mathrm{L})$, which correspond to residual turbidity removals of $75 \%$, $20686 \%$ and $83 \%$, respectively. The significant reduction in membrane fouling by MO coagulation 207 is due likely to the improved transformation and removal efficiency of colloids from water prior 208 to MF treatment. During the coagulation and sedimentation processes, aggregation of small 209 colloids and dissolved matter can lead to a larger and effective particle size, which can result in 210 less specific membrane resistance. ${ }^{34}$ In addition, organic matter and colloidal particles 211 transformed into flocs can easily be removed by backwashing. ${ }^{35}$ The results revealed that the 212 effect of fouling mitigation by MO coagulation can be maximized at $2 \mathrm{~mL}-\mathrm{MO} / \mathrm{L}$ dose, which 213 resulted in only an increased TMP from 12.0 to $12.4 \mathrm{kPa}$ over three filtration cycles (Fig. 2). In 214 contrast, $3 \mathrm{~mL}-\mathrm{MO} / \mathrm{L}$ appeared to be an overdose, resulting in a discernible increase in TMP 215 from 12 to $15 \mathrm{kPa}$ in three filtration cycles. Likewise, a lower dose at $1 \mathrm{~mL}-\mathrm{MO} / \mathrm{L}$ was not 216 sufficient to effectively mitigate membrane fouling. The results here indicate that the MO dose 217 optimised for turbidity removal can be an important control parameter for membrane fouling 
218 mitigation in MF process. Therefore, monitoring turbidity in MF feed (i.e. coagulation effluent)

219 can be an operating parameter to maintain the minimum level of membrane fouling.

220 Membrane fouling during MF treatment without pretreatment was further analyzed using the 221 filtration model that can differentiate three pore blocking and one cake filtration mechanisms. It

222 is noted that the results during MF treatment with MO coagulation could not be analyzed using 223 the filtration model, because the TMP increase was too small for an accurate model fitting. 224 Overall, membrane fouling during MF treatment progressed following the cake layer filtration 225 mechanism. The slope $(n)$ calculated based on the data during the all filtration cycles were close 226 to zero $(n=-0.2-0.3)$ when the last twelve minutes data of $2^{\text {nd }}$ and $3^{\text {rd }}$ filtration cycle was 227 excluded (Fig. 3). Nevertheless, during the last twelve minutes of the $2^{\text {nd }}$ and $3^{\text {rd }}$ filtration cycle, 228 the slope $(n)$ increased considerably $(n=5-7)$, which was far beyond the slope range of the 229 filtration model. These sudden increases may have occurred through the compression of the cake 230 layer, which could be induced by high feed pressure according to the progress of membrane 231 fouling. ${ }^{36-38}$ The compressed cake layer on the membrane surface can cause more packed fouling 232 structure, which can increase the significant increase in hydraulic resistance to permeating water. 233 Overall, the results here suggest that MO coagulation can effectively reduce foulants that form 234 cake layer on the membrane surface and act as hydraulic resistance. 


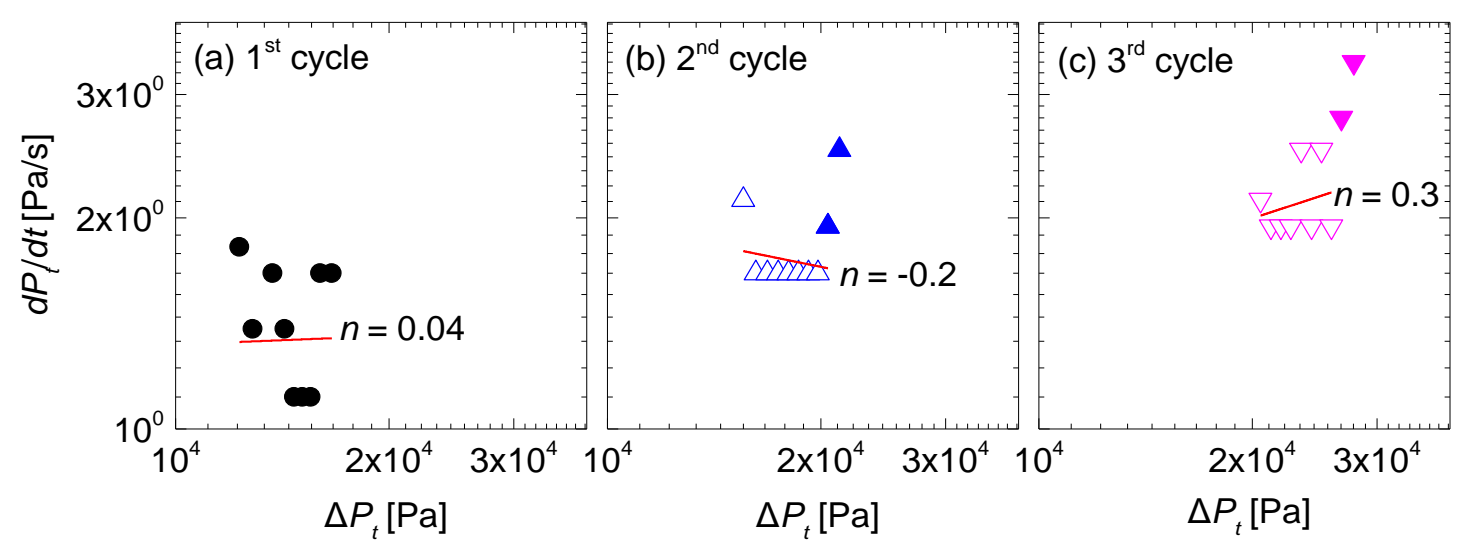

236 Fig. 3 - The derivatives $d P_{t} / d t$ as a function of TMP during MF treatment without pretreatment. 237 The last 12 minute data in the $2^{\text {nd }}$ and $3^{\text {rd }}$ cycle was presented in solid symbol.

\subsection{Optimisation of water $\mathrm{pH}$ for fouling mitigation}

239 The impact of water $\mathrm{pH}$ on the removal of turbidity and colour by MO coagulant was evaluated 240 at the optimum MO coagulant dose $(2 \mathrm{~mL}-\mathrm{MO} / \mathrm{L})$. As reported in section 3.1, MO coagulant did 241 not alter water $\mathrm{pH}$, thus water $\mathrm{pH}$ was adjusted prior to coagulation. As a result, negligible 242 impact was identified throughout the tested $\mathrm{pH}$ (5.5-9.5) (Fig. 4). A similar observation with 243 negligible impact of water $\mathrm{pH}$ on turbidity removal by $\mathrm{MO}$ coagulation has been reported in a 244 previous literature. ${ }^{39} \mathrm{MO}$ coagulant in water at the tested $\mathrm{pH}$ is positively charged due to the 245 isoelectric $\mathrm{pH}$ of the cationic proteins at $10{ }^{8}$ Because colloidal particles in natural water are 246 usually negatively charged, the dominant mechanisms of coagulant of charge neutralisation and 247 adsorption effects ${ }^{10}$ can effectively occur at the experiment $\mathrm{pH}$ value. This is a notable advantage 248 over alum, which often requires $\mathrm{pH}$ adjustment for successful coagulation. A slightly high 249 residual turbidity and colour was observed at the lowest $\mathrm{pH}$ (5.5). This may be due to the 250 increased positive charge of the MO coagulant and reduced negative charge of particles in water. 

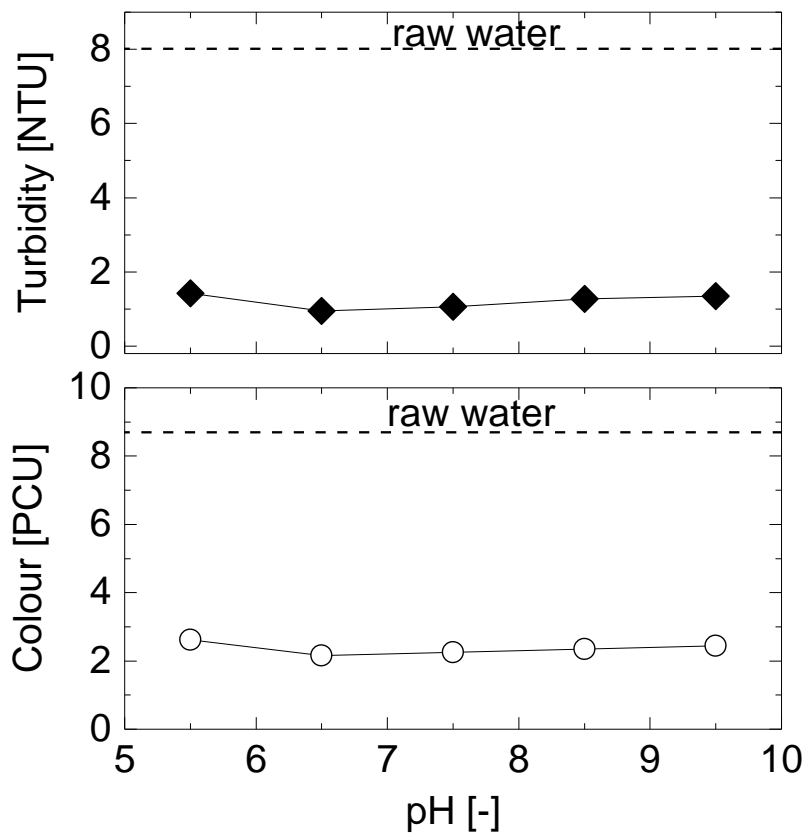

Fig. 4 - Removal of turbidity and colour by optimum MO coagulant dose (2 mL-MO/L) at 253 variable water $\mathrm{pH}$ in the surface water. Optimisation of MO coagulant dose for the specific river 254 water is provided in Fig. S2.

255 The waters treated by MO coagulation at three $\mathrm{pH}(5.5,6.5$ and 7.5$)$ were used to evaluate the 256 impact of $\mathrm{MO}$ coagulation $\mathrm{pH}$ on $\mathrm{MF}$ membrane fouling. Over the three filtration cycles, a 257 negligible difference was observed for $\mathrm{pH} 6.5$ and 7.5 (Fig. 5). Coagulation using a surface water 258 is typically performed within the $\mathrm{pH}$ range. A slightly higher TMP was observed for $\mathrm{pH} 5.5$, 259 which is in line with the results for turbidity removal. This indicates that turbidity removal by 260 MO coagulation is a key for achieving the optimum effect of membrane fouling mitigation. 261 Overall, the results indicate that $\mathrm{pH}$ adjustment prior to MO coagulant is not necessary to achieve 262 the optimum coagulation and fouling mitigation. 


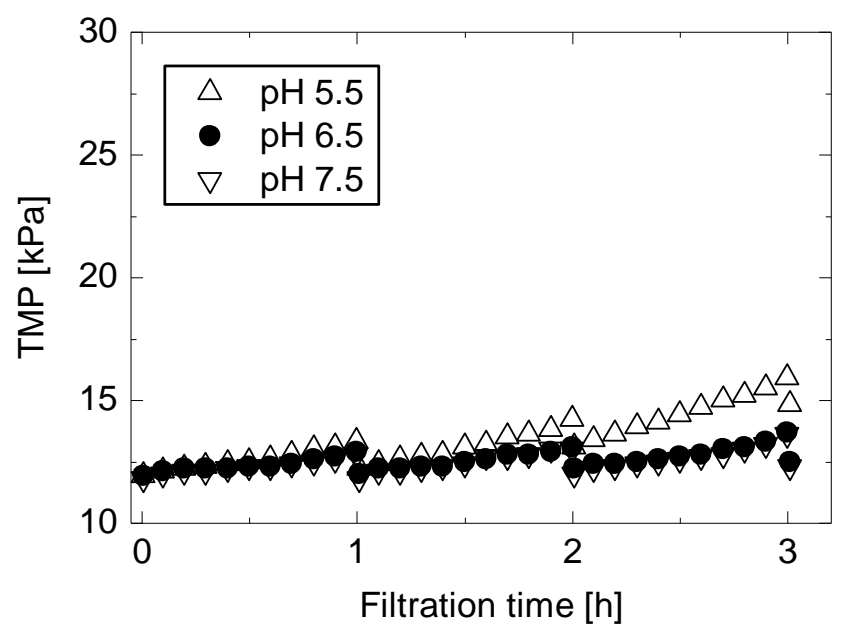

264 Fig. 5 - Effect of water pH in MF treatment of waters treated with the optimum MO coagulant 265 dose of $2 \mathrm{~mL}-\mathrm{MO} / \mathrm{L}$ (permeate flux $=140 \mathrm{~L} / \mathrm{m}^{2} \mathrm{~h}$, backwashing flux $=280 \mathrm{~L} / \mathrm{m}^{2} \mathrm{~h}$ and 266 backwashing time $=1 \mathrm{~min})$.

\section{$267 \quad 3.4 \quad$ Comparison with alum coagulation}

\section{3.4.1 Membrane fouling}

269 To demonstrate the potential of $\mathrm{MO}$ as an alternative coagulant of alum for MF treatment, the 270 effect of pretreatment on fouling mitigation between $\mathrm{MO}(2 \mathrm{~mL}-\mathrm{MO} / \mathrm{L})$ and alum $(4 \mathrm{mg}-\mathrm{Al} / \mathrm{L})$ 271 coagulation was compared. For both coagulants, minor fouling development was observed 272 during filtration (Fig. 6). MF treatment of the MO-treated river water revealed an increase in 273 TMP from 12 to $15 \mathrm{kPa}$ over six filtration cycles. In contrast, alum coagulation prior to MF 274 treatment resulted in a less increase in TMP from 12 to $13 \mathrm{kPa}$. Despite of the relatively large 275 difference in residual turbidity between the two coagulants $(\mathrm{MO}=1.1 \mathrm{NTU}$ and alum $=0.1$ 276 NTU), they effectively mitigated membrane fouling and the subsequent increase in TMP after six

277 filtration cycles was comparable between $\mathrm{MO}$ and alum (TMP $=15$ and $13 \mathrm{kPa}$, respectively). 278 This was also confirmed in a separate test (Fig. S3). These results indicate that sufficient level of 
membrane fouling mitigation in MF can be achieved through MO coagulation. In addition, the

280 results suggest that MO is a good alternative to alum and other conventional chemical coagulants

281 for coagulation pre-treatment prior to MF. Further improvement for membrane fouling

282 mitigation by MO coagulation can be expected by further optimising coagulation or filtration

283 conditions. Coagulation condition includes water $\mathrm{pH}$, and filtration conditions include permeate

284 flux and frequency of backwashing. In addition, modification on the extraction method of MO

285 coagulant from seeds may improve coagulation performance in terms of turbidity removal,

286 which can enhance membrane fouling mitigation. However, these further optimisations are

287 beyond the scope of this study and will be addressed in the future study.

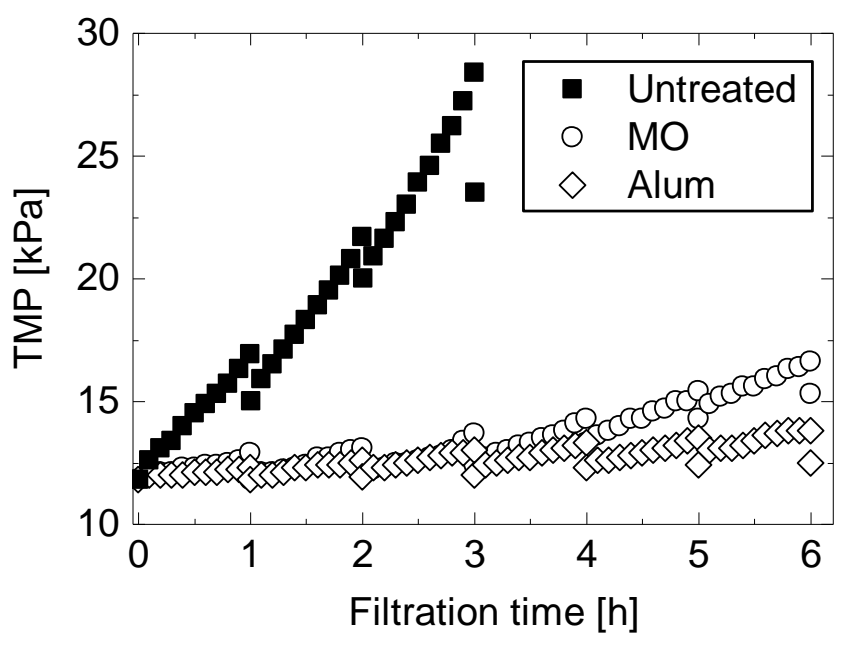

Filtration time $[\mathrm{h}]$

289 Fig. 6 - Fouling development in MF treatment without pretreatment, with MO coagulation at 2 $290 \mathrm{~mL}-\mathrm{MO} / \mathrm{L}$ or with alum coagulation at $4 \mathrm{mg}-\mathrm{Al} / \mathrm{L}$ (permeate flux $=140 \mathrm{~L} / \mathrm{m}^{2} \mathrm{~h}$, backwashing flux $291=280 \mathrm{~L} / \mathrm{m}^{2} \mathrm{~h}$ and backwashing time $\left.=1 \mathrm{~min}\right)$.

292 To provide further understanding in the difference of fouling mitigation level between MO and 293 alum coagulation, zeta potential of suspended particles before and after coagulation treatment 294 with MO and alum was determined. Zeta potential of suspended particles changed $-10 \pm 2.9 \mathrm{mV}$ 
295 (untreated water) to $+0.5 \pm 5.2 \mathrm{mV}$ (after alum coagulation) and $-17.0 \pm 5.8 \mathrm{mV}$ (after $\mathrm{MO}$ 296 coagulation). In other words, alum coagulation resulted in the neutralization of residual 297 suspended particles while MO coagulation rendered residual suspended particles even more 298 negatively charged. PVDF membranes are also negatively charged at environmental $\mathrm{pH}(\mathrm{pH}$ $299 \sim 6)^{13}$. Thus, charge neutralization of suspended particles by alum coagulation is expected to 300 exacerbate membrane fouling. In contrast, electrostatic repulsion between negatively charged 301 suspended particles after MO coagulation and the negatively charged MF membrane surface can 302 reduce membrane fouling. However, alum coagulation resulted in slightly better fouling 303 mitigation than MO coagulation (Fig. 6). Thus, it is possible that the contribution of electrostatic 304 repulsion was small to alleviate fouling was small in comparison with the contribution from 305 residual organic substances dissolved in water.

306 Additional analysis of particle size distribution revealed that both MO and alum coagulation 307 were effective to remove suspended particles in the range of 100-600 $\mathrm{nm}$ in size (Fig. 7). 308 Compared to MO coagulation, alum coagulation could remove suspended particles in the range 309 of $100-180$ and $320-420 \mathrm{~nm}$ more effectively than those in the range of $180-320 \mathrm{~nm}$. 310 Nevertheless, further research is necessary to clarify the contribution of each size fraction to 311 membrane fouling. Considering that cake layer is the dominant mechanism of membrane fouling 312 without coagulation, the reduction in the number of particles over $200 \mathrm{~nm}$ (nominal pore size of 313 the membrane) was expected to play a role in mitigation membrane fouling through alum or MO 314 coagulation. 


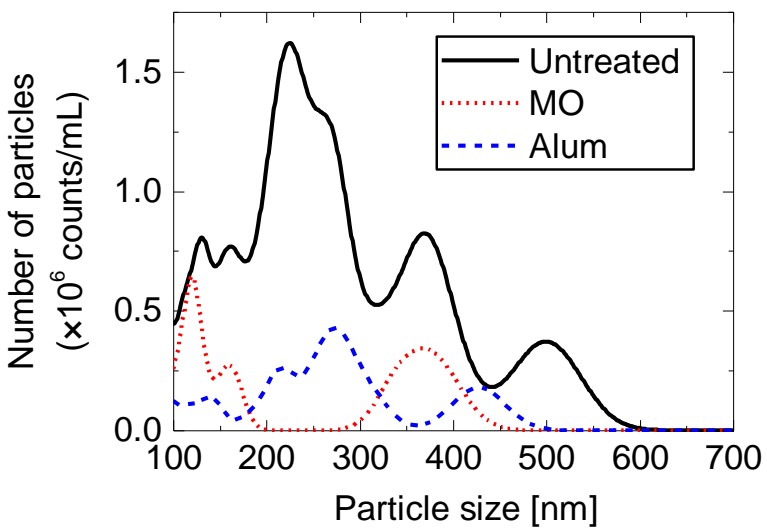

316 Fig. 7 - Particle size distribution of waters without pretreatment, with MO coagulation or with 317 alum coagulation at their optimum doses ( $2 \mathrm{~mL}-\mathrm{MO} / \mathrm{L}$ and $4 \mathrm{mg}-\mathrm{Al} / \mathrm{L})$.

\section{$318 \quad 3.4 .2$ Water quality}

319 Despite of the difference in coagulation-treated water quality between MO and alum coagulation, 320 water quality after MF treatment was comparable. For example, turbidity and colour in MF

321 permeate was not detectable or almost zero for both coagulants (Table 2), indicating that MF 322 treatment plays a major role in the reduction of turbidity and colour. In contrast, conductivity and 323 TOC in MF permeate varied notably due to the difference in coagulation performance (Table 1) 324 and the incapability of MF for their removal. MF membrane is not capable of removing 325 dissolved ions, resulting in the difference in conductivity in MF permeate ( 275 and $312 \mu \mathrm{S} / \mathrm{cm}$ 326 for MO and alum, respectively). Likewise, TOC in MF permeate of the MO treated river water 327 was as high as $15.3 \mathrm{mg} / \mathrm{L}$, which was $2.9 \mathrm{mg} / \mathrm{L}$ higher than that of the alum-treated river water. 328 An advantage of $\mathrm{MO}$ over alum was water $\mathrm{pH}$. Water $\mathrm{pH}$ is an important parameter in product 329 water to avoid damaging infrastructure in a water distribution network. MO coagulation followed 330 by MF treatment maintained water $\mathrm{pH}$ almost constant at 7.4, which is within the recommended 331 range of $6.5-7.5$ by $\mathrm{WHO}$ guidelines. ${ }^{3}$ By contrast, alum coagulation reduced the water $\mathrm{pH}$ from 
3327.4 to 6.3 (below the WHO guideline level), and it remained unchanged after MF treatment. This 333 necessitates $\mathrm{pH}$ adjustment by addition of chemical reagents, which is a cost factor.

334 Table 2 - Water quality in MF permeate of raw river water, MO and alum treated-river water 335 with the optimum coagulant doses ( $2 \mathrm{~mL}-\mathrm{MO} / \mathrm{L}$ and $4 \mathrm{mg}-\mathrm{Al} / \mathrm{L})$ during the $1^{\text {st }}$ filtration cycle: 336 The average and ranges of in in Fig. 6 and Fig. S3.

\begin{tabular}{lccc}
\hline Parameter & $\begin{array}{c}\text { Untreated river water } \\
(\text { control })\end{array}$ & $\begin{array}{c}\text { MO treated } \\
\text { river water }\end{array}$ & $\begin{array}{c}\text { Alum treated } \\
\text { river water }\end{array}$ \\
\hline Turbidity $(\mathrm{NTU})$ & $0.2 \pm 0.1$ & 0.0 & 0.0 \\
Colour $(\mathrm{PCU})$ & $1.9 \pm 0.1$ & $0.3 \pm 0.1$ & $0.0 \pm 0.0$ \\
Conductivity $(\mu \mathrm{S} / \mathrm{cm})$ & $257 \pm 1.0$ & $275 \pm 2.0$ & $312 \pm 2.0$ \\
$\mathrm{TOC}(\mathrm{mg} / \mathrm{L})$ & $15.3 \pm 0.1$ & $15.3 \pm 0.1$ & $12.4 \pm 0.1$ \\
$\mathrm{pH}$ & $7.4 \pm 0.0$ & $7.4 \pm 0.0$ & $6.3 \pm 0.1$ \\
\hline
\end{tabular}

\section{4. Conclusions}

338 Pre-treatment of the surface river with pre-filtered MO and alum at their optimum doses led to a 339 substantial reduction in membrane fouling. Despite of the relatively large difference in residual 340 turbidity after MO (1.1 NTU) and alum (0.1 NTU) coagulation, their membrane fouling levels on 341 MF treatment did not differ significantly over six filtration cycles. This indicates that sufficient 342 level of fouling mitigation in MF can be readily achieved through MO coagulation. Major water 343 quality (turbidity and colour) after MF treatment was comparable between MO and alum 344 coagulation. While MO coagulation slightly increased the load of organics, alum notably 345 increased conductivity. MO coagulation did not change water $\mathrm{pH}$, which is advantageous over 346 alum coagulation, because post treatment for $\mathrm{pH}$ adjustment can be avoided. The results reported 347 here suggest that $\mathrm{MO}$ is a good alternative coagulant to mitigate membrane fouling of $\mathrm{MF}$ 348 treatment for decentralised drinking water applications. 


\section{Acknowledgements}

350 We thank Master's Degree and Internship Program of African Business Education Initiative for

351 Youth for providing scholarship to Mr. Ronald Katalo. We also thank Atsushi Kitano and Riku

352 Kojima at Ryukoku University for their assistance in the analysis of zeta potential and particle

353 size distribution.

354 6. Conflicts of interest

355 There are no conflicts to declare.

\section{References}

1. S. Subramanium, V. Nand, M. Maata and K. Koshy, Moringa oleifera and other local seeds in water purification in developing countries. Research Journal of Chemistry and Environment, 2011, 15, 135-138.

2. F. P. Camacho, V. S. Sousa, R. Bergamasco and M. Ribau Teixeira, The use of Moringa oleifera as a natural coagulant in surface water treatment. Chemical Engineering Journal, 2017, 313, 226-237.

3. B. Gordon, P. Callan and C. Vickers, WHO guidelines for drinking-water quality. WHO chronicle, 2008, 38, 564-564.

4. H. M. Kwaambwa and R. Maikokera, A fluorescence spectroscopic study of a coagulating protein extracted from Moringa oleifera seeds. Colloids and Surfaces B: Biointerfaces, 2007, 60, 213-220.

6. S. Katayon, M. J. M. M. Noor, M. Asma, L. A. A. Ghani, A. M. Thamer, I. Azni, J.

5. T. Okuda, A. U. Baes, W. Nishijima and M. Okada, Coagulation mechanism of salt solution-extracted active component in Moringa oleifera seeds. Water Research, 2001, 35, 830-834. Ahmad, B. C. Khor and A. M. Suleyman, Effects of storage conditions of Moringa oleifera seeds on its performance in coagulation. Bioresource Technology, 2006, 97, 1455-1460. 
7. T. Nkurunziza, J. B. Nduwayezu, E. N. Banadda and I. Nhapi, The effect of turbidity levels and Moringa oleifera concentration on the effectiveness of coagulation in water treatment. Water Science and Technology, 2009, 59, 1551-1558.

8. A. Ndabigengesere, K. S. Narasiah and B. G. Talbot, Active agents and mechanism of coagulation of turbid waters using Moringa oleifera. Water Research, 1995, 29, 703-710.

9. K. A. Ghebremichael, K. R. Gunaratna, H. Henriksson, H. Brumer and G. Dalhammar, A simple purification and activity assay of the coagulant protein from Moringa oleifera seed. Water Research, 2005, 39, 2338-2344.

10. C.-Y. Yin, Emerging usage of plant-based coagulants for water and wastewater treatment. Process Biochemistry, 2010, 45, 1437-1444.

11. D. Lee, Y. Lee, S. S. Choi, S.-H. Lee, K.-W. Kim and Y. Lee, Effect of membrane property and feed water organic matter quality on long-term performance of the gravitydriven membrane filtration process. Environmental Science and Pollution Research, 2017, Doi:10.1007/s11356-017-9627-8.

12. R. Butler, Skyjuice technology impact on the U.N. MDG outcomes for safe affordable potable water. Desalination, 2009, 248, 622-628.

13. A. I. Schäfer, U. Schwicker, M. M. Fischer, A. G. Fane and T. D. Waite, Microfiltration of colloids and natural organic matter. Journal of Membrane Science, 2000, 171, 151172.

14. V. Starov, D. Lloyd, A. Filippov and S. Glaser, Sieve mechanism of microfiltration separation. Separation and Purification Technology, 2002, 26, 51-59.

15. T. Carroll, S. King, S. R. Gray, B. A. Bolto and N. A. Booker, The fouling of microfiltration membranes by NOM after coagulation treatment. Water Research, 2000, 34, 2861-2868.

16. W. Yuan and A. L. Zydney, Humic acid fouling during microfiltration. Journal of Membrane Science, 1999, 157, 1-12.

17. E. Iritani, N. Katagiri, T. Takenaka and Y. Yamashita, Membrane pore blocking during cake formation in constant pressure and constant flux dead-end microfiltration of very dilute colloids. Chemical Engineering Science, 2015, 122, 465-473.

18. A. I. Schäfer, A. G. Fane and T. D. Waite, Cost factors and chemical pretreatment effects in the membrane filtration of waters containing natural organic matter. Water Research, 2001, 35, 1509-1517.

19. S. A. Alizadeh Tabatabai, J. C. Schippers and M. D. Kennedy, Effect of coagulation on fouling potential and removal of algal organic matter in ultrafiltration pretreatment to seawater reverse osmosis. Water Research, 2014, 59, 283-294. 
20. X. Zhang, L. Fan and F. A. Roddick, Effect of feedwater pre-treatment using UV oxidation for mitigating the fouling of a ceramic MF membrane caused by soluble algal organic matter. Journal of Membrane Science, 2015, 493, 683-689.

21. C. Jung, S. Han and L. Kang, Characteristic of organic substances adsorption onto membrane materials. Journal of Korean Society of Environmental Engineers 2002, 24, 1339-1348.

22. D. M. Formentini-Schmitt, Á. C. D. Alves, M. T. Veit, R. Bergamasco, A. M. S. Vieira and M. R. Fagundes-Klen, Ultrafiltration combined with coagulation/flocculation/sedimentation using moringa oleifera as coagulant to treat dairy industry wastewater. Water, Air, and Soil Pollution, 2013, 224, 1682.

23. G. A. P. Mateus, D. M. Formentini-Schmitt, L. Nishi, M. R. Fagundes-Klen, R. G. Gomes and R. Bergamasco, Coagulation/flocculation with Moringa oleifera and membrane filtration for dairy wastewater treatment. Water, Air, \& Soil Pollution, 2017, 228, 342.

24. S. Katayon, M. J. Megat Mohd Noor, W. Kien Tat, G. Abdul Halim, A. M. Thamer and Y. Badronisa, Effect of natural coagulant application on microfiltration performance in treatment of secondary oxidation pond effluent. Desalination, 2007, 204, 204-212.

25. A. T. A. Baptista, P. F. Coldebella, P. H. F. Cardines, R. G. Gomes, M. F. Vieira, R. Bergamasco and A. M. S. Vieira, Coagulation-flocculation process with ultrafiltered saline extract of moringa oleifera for the treatment of surface water. Chemical Engineering Journal, 2015, 276, 166-173.

26. G. S. Madrona, G. B. Serpelloni, A. M. Salcedo Vieira, L. Nishi, K. C. Cardoso and R. Bergamasco, Study of the effect of Saline solution on the extraction of the Moringa oleifera seed's active component for water treatment. Water, Air, and Soil Pollution, 2010, 211, 409-415.

27. T. Okuda, A. U. Baes, W. Nishijima and M. Okada, Improvement of extraction method of coagulation active components from Moringa oleifera seed. Water Research, 1999, 33, 3373-3378.

28. E. Iritani, A review on modeling of pore-blocking behaviors of membranes during pressurized membrane filtration. Drying Technol., 2013, 31, 146-162.

29. F. Wang and V. V. Tarabara, Pore blocking mechanisms during early stages of membrane fouling by colloids. J. Colloid Interface Sci., 2008, 328, 464-469.

30. C.-C. Ho and A. L. Zydney, Transmembrane pressure profiles during constant flux microfiltration of bovine serum albumin. J. Membr. Sci., 2002, 209, 363-377.

31. C. A. Okuofu, Coagulation of low turbidity surface waters with moringa oleifera seeds. International Journal of Environmental Studies, 1995, 48, 263-273. 
32. T. Okuda, A. U. Baes, W. Nishijima and M. Okada, Isolation and characterization of coagulant extracted from Moringa oleifera seed by salt solution. Water Research, 2001, 35, 405-410.

33. A. Matilainen, M. Vepsäläinen and M. Sillanpää, Natural organic matter removal by coagulation during drinking water treatment: A review. Advances in Colloid and Interface Science, 2010, 159, 189-197.

34. C. W. Jung, H. J. Son and L. S. Kang, Effects of membrane material and pretreatment coagulation on membrane fouling: fouling mechanism and NOM removal. Desalination, 2006, 197, 154-164.

35. J. Moon, M. S. Kang, J. L. Lim, C. H. Kim and H. D. Park, Evaluation of a low-pressure membrane filtration for drinking water treatment: pretreatment by coagulation/sedimentation for the MF membrane. Desalination, 2009, 247, 271-284.

36. J. C. Schippers and J. Verdouw, The modified fouling index, a method of determining the fouling characteristics of water. Desalination, 1980, 32, 137-148.

37. K. Listiarini, D. D. Sun and J. O. Leckie, Organic fouling of nanofiltration membranes: Evaluating the effects of humic acid, calcium, alum coagulant and their combinations on the specific cake resistance. J. Membr. Sci., 2009, 332, 56-62.

38. S. A. Mourouzidis-Mourouzis and A. J. Karabelas, Whey protein fouling of microfiltration ceramic membranes-Pressure effects. J. Membr. Sci., 2006, 282, 124132.

39. A. Ndabigengesere and K. S. Narasiah, Influence of operating parameters on turbidity removal by coagulation with moringa oleifera seeds. Environmental Technology, 1996, 17, 1103-1112. 